Article

\title{
Amine-grafted on lanthanide metal-organic frameworks: Three solid base catalysts for Knoevenagel condensation reaction
}

\author{
Yanwei Ren ${ }^{\text {a,* }}$, Jiaxian Lu a, Ou Jiang b, Xiaofei Cheng a , Jun Chen ${ }^{b}$ \\ a School of Chemistry and Chemical Engineering, South China University of Technology, Guangzhou 510641, Guangdong, China \\ b Guangdong Winner Functional Materials Co., Ltd, Foshan 528521, Guangdong, China
}

A R T I C L E I N F O

Article history:

Received 29 May 2015

Accepted 3 July 2015

Published 20 November 2015

\section{Keywords:}

Lanthanide metal-organic framework

Post-synthetic modification

Solid base catalyst

Knoevenagel condensation reaction

Size-selective catalysis

\begin{abstract}
A B S T R A C T
A post-synthetic modification strategy has been used to prepare three solid base catalysts, including $\operatorname{Er}(\mathrm{btc})(\mathrm{ED})_{0.75}\left(\mathrm{H}_{2} \mathrm{O}\right)_{0.25}$ (2, btc $=1$,3,5-benzenetricarboxylates, $\mathrm{ED}=1$,2-ethanediamine), $\operatorname{Er}(\mathrm{btc})(\mathrm{PP})_{0.55}\left(\mathrm{H}_{2} \mathrm{O}\right)_{0.45}(\mathbf{3}, \mathrm{PP}=$ piperazine $)$, and $\operatorname{Er}(\mathrm{btc})(\mathrm{DABCO})_{0.15}\left(\mathrm{H}_{2} \mathrm{O}\right)_{0.85}(\mathbf{4}, \mathrm{DABCO}=1,4-$ diazabicyclo[2.2.2] octane), by grafting three different diamines onto the coordinatively unsaturated $\operatorname{Er}(\mathrm{III})$ ions into the channels of the desolvated lanthanide metal-organic framework (Er(btc)). The resulting metal-organic frameworks were characterized by elemental analysis, thermogravimetric analysis, powder X-ray diffraction, and $\mathrm{N}_{2}$ adsorption. Based on its higher loading ratio of the diamine, as well as its greater stability and porosity, catalyst 2 exhibited higher catalytic activity and reusability than catalysts $\mathbf{3}$ and $\mathbf{4}$ for the Knoevenagel condensation reaction. The catalytic mechanism of $\mathbf{2}$ has also been investigated using size-selective catalysis tests.
\end{abstract}

(C) 2015, Dalian Institute of Chemical Physics, Chinese Academy of Sciences. Published by Elsevier B.V. All rights reserved.

\section{Introduction}

Metal-organic frameworks (MOFs) constructed from metal ions (or metal ion clusters) and bridging organic linkers as a rapidly growing class of new materials [1-5] have attracted considerable interest because of their high porosity, tunable pores, diverse structures, and potential applications. MOFs, in particular, have shown great promise as heterogeneous catalysts [6-8] because they offer several advantages over conventional immobilized catalyst systems such as well-defined structure with uniformly accessible catalytic centers. Among the MOFs reported to date, lanthanide MOFs (Ln-MOFs) have shown the greatest potential as heterogeneous catalysts because of the flexible coordination sphere of the lanthanide ion, which can create a coordinatively unsaturated metal center. Furthermore, Ln-MOFs generally exhibit high thermal stability.
Based on their interesting properties, several research groups, including our own, have been working on the development of new strategies for the crystal engineering of porous Ln-MOFs and their application in heterogeneous catalysis [9-16].

Post-synthetic modification (PSM) is an efficient method for the production of novel materials that contain the intrinsic characteristics of MOFs, including open porosities, large surface areas, and regular structures [17-19]. PSM can be achieved by the formation of a covalent attachment to the organic linkers [20-23] or by the grafting of organic molecules at coordinatively unsaturated metal sites [24-27]. The latter of these two strategies involves the use of a reagent to modify the components of the MOF (e.g., a secondary building unit or an organic linker) by forming a new dative bond. PSM is particularly attractive for the production of materials to be used as catalysts because it opens the possibility of employing a wide range of

\footnotetext{
* Corresponding author. Tel: +86-20-87112053; Fax: +86-20-87113735; E-mail: renyw@scut.edu.cn This work was supported by the National Natural Science Foundation of China (21372087). 
catalytically active organic groups in MOFs, as well as other attendant metal ions. There have been many reports in the literature pertaining to the catalytic properties of MOFs prepared using a PSM strategy [23,24,28-30].

In an attempt to develop efficient new catalysts based on Ln-MOFs, we investigated the application of a PSM strategy to the Ln-MOF $\left[\operatorname{Er}(\mathrm{btc})\left(\mathrm{H}_{2} \mathrm{O}\right)\right] \cdot \mathrm{DMF}_{0.7}(\mathbf{1})$, which has high porosity and good stability (btc $=1,3,5$-benzenetricarboxylates). Three different diamines, 1,2-ethanediamine (ED), piperazine (PP), and 1,4-diazabicyclo[2.2.2] octane (DABCO), which represent a variety of molecular size and basicity properties, were grafted onto the coordinatively unsaturated $\operatorname{Er}($ III) ions of desolvated 1. This grafting process resulted in the formation of several new solid base catalysts, including $\operatorname{Er}(\mathrm{btc})(\mathrm{ED})_{0.75}\left(\mathrm{H}_{2} \mathrm{O}\right)_{0.25}(2)$, $\operatorname{Er}(\mathrm{btc})(\mathrm{PP})_{0.55}\left(\mathrm{H}_{2} \mathrm{O}\right)_{0.45}$ (3), and $\mathrm{Er}(\mathrm{btc})(\mathrm{DABCO})_{0.15}\left(\mathrm{H}_{2} \mathrm{O}\right)_{0.85}$ (4) (Scheme 1). In these catalysts, one of the nitrogen atoms of the diamine was coordinated to an $\operatorname{Er}(\mathrm{III})$ ion, whereas the other nitrogen atom acted as a catalytically active site in channels of the MOF. The catalytic properties of these three solid catalysts were tested against the Knoevenagel condensation reaction, and a plausible mechanism was proposed for catalyst 2 based on the results of a series of size-selective catalysis tests.

\section{Experimental}

\subsection{General information}

All of the chemicals used in the current study were purchased from Alfa or TCI and used directly without purification. Single crystal X-ray diffraction analysis was performed on a Rigaku Mercury CCD diffractometer operated at $90 \mathrm{kV}$ and 50 $\mathrm{mA}$ using Mo $K_{\alpha}$ radiation $(\lambda=0.071073 \mathrm{~nm})$ at room temperature. The structure was solved by direct methods, and all of the non-hydrogen atoms were refined anisotropically by leastsquares on $\mathrm{F}^{2}$ using the SHELXTL program. Hydrogen atoms on the organic ligands were generated using the riding mode. Powder X-ray diffraction (PXRD) patterns were collected on a Bruker D8 powder diffractometer at $40 \mathrm{kV}$ and $40 \mathrm{~mA}$ using $\mathrm{Cu}$ $K_{\alpha}$ radiation $(\lambda=0.15406 \mathrm{~nm})$, with a scan speed of $17.7 \mathrm{~s} / \mathrm{step}$ and a step size of $0.02^{\circ}(2 \theta)$. Thermogravimetric analysis (TGA) was performed on a Q600 SDT instrument under a steady flow of $\mathrm{N}_{2}$ at a heating rate of $10{ }^{\circ} \mathrm{C} / \mathrm{min}$ from ambient temperature to $800{ }^{\circ} \mathrm{C}$. Nitrogen adsorption measurements were carried out at $-196^{\circ} \mathrm{C}$ on a micromeritics ASAP $2020 \mathrm{M}$ instrument. Elemental analyses for $\mathrm{C}, \mathrm{H}$, and $\mathrm{N}$ were conducted on a Vario EL

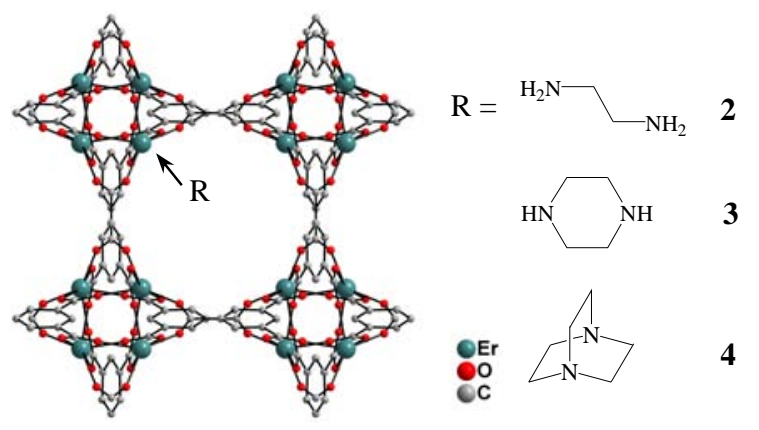

Scheme 1. The structure of catalysts 2,3 , and 4 .
III Elemental Analyzer. Infrared (IR) spectra were measured as KBr pellets on a Nicolet Model Nexus 470 FT-IR spectrometer at wavenumbers in the range of $4000-400 \mathrm{~cm}^{-1}$. ${ }^{1} \mathrm{H}$ NMR spectra were recorded on a Bruker Model AM-400 (400 MHz) spectrometer. Gas chromatography-mass spectroscopy (GC-MS) was conducted on a Shimadzu GCMSQP5050A system equipped with a $0.25 \mathrm{~mm} \times 30 \mathrm{~m}$ DB-WAX capillary column.

\subsection{Preparation of the catalysts}

For preparation of $\left[\operatorname{Er}(\mathrm{btc})\left(\mathrm{H}_{2} \mathrm{O}\right)\right] \cdot \mathrm{DMF}_{0.7}(\mathbf{1})$, pre-functionalized MOF 1 was synthesized according to a previously reported procedure [31]. $\operatorname{Er}\left(\mathrm{NO}_{3}\right)_{3} \cdot 6 \mathrm{H}_{2} \mathrm{O}(0.231 \mathrm{~g}, 0.5 \mathrm{mmol})$ and $\mathrm{H}_{3}$ btc $(0.053 \mathrm{~g}, 0.25 \mathrm{mmol})$ were dispersed in a mixture of DMF (4 mL) and $\mathrm{H}_{2} \mathrm{O}(4 \mathrm{~mL})$, and the resulting mixture was heated at $105^{\circ} \mathrm{C}$ for $24 \mathrm{~h}$ in a sealed Teflon reactor. The mixture was then cooled to ambient temperature and purified by centrifugation to give pure pink crystalline needles, which were dried at ambient temperature. [ $\left.\mathrm{Er}(\mathrm{btc})\left(\mathrm{H}_{2} \mathrm{O}\right)\right] \cdot \mathrm{DMF}_{0.7}$ (1): calcd. C 30.06, $\mathrm{H}$ 2.25, N 2.21; found: C 30.38, H 2.11, N 2.34. IR spectrum ( $\left.\mathrm{cm}^{-1}\right)$ : 3068 (w), 1628 (m), 1577 (w), 1445 (m), 1385 (s), 1213 (m), $1105(\mathrm{w}), 944(\mathrm{w}), 824(\mathrm{w}), 765(\mathrm{~m}), 738(\mathrm{~m}), 708(\mathrm{~s}), 566(\mathrm{~m})$, $457(\mathrm{w})$.

For preparation of $\mathrm{Er}(\mathrm{btc})(\mathrm{ED})_{0.75}\left(\mathrm{H}_{2} \mathrm{O}\right)_{0.25}$ (2), after being dehydrated under vacuum at $180^{\circ} \mathrm{C}$ for $8 \mathrm{~h}, 0.5 \mathrm{~g}$ of desolvated 1 was suspended in $30 \mathrm{~mL}$ of anhydrous toluene, followed by $0.1 \mathrm{~g}$ (1.6 mmol) ED, and the resulting suspension was stirred at room temperature over night. The mixture was then filtered, and the resulting pink powder was washed sequentially with anhydrous toluene and anhydrous diethyl ether (three times each), and then dried at room temperature for $12 \mathrm{~h}$. $\mathrm{Er}(\mathrm{btc})(\mathrm{ED})_{0.75}\left(\mathrm{H}_{2} \mathrm{O}\right)_{0.25}$ (2): calcd. C 29.75, $\mathrm{H}$ 2.26, $\mathrm{N}$ 4.96; found: C 28.96, H 2.52, N 5.17. IR spectrum (cm-1): $3363(\mathrm{w})$, 3066 (w), 1613 (m), 1578 (w), 1451 (m), 1364 (s), 1210 (m), $1102(\mathrm{w}), 946(\mathrm{w}), 823(\mathrm{w}), 761(\mathrm{~m}), 737$ (m), $708(\mathrm{~s}), 566(\mathrm{w})$, $535(\mathrm{w}), 440(\mathrm{w})$.

$\operatorname{Er}(\mathrm{btc})(\mathrm{PP})_{0.55}\left(\mathrm{H}_{2} \mathrm{O}\right)_{0.45}(3)$ was prepared in a similar manner to catalyst 2, except that ED was replaced with PP and the suspension was heated to $40{ }^{\circ} \mathrm{C}$ to allow for the dissolution of the solid amine. $\operatorname{Er}(\mathrm{btc})(\mathrm{PP})_{0.55}\left(\mathrm{H}_{2} \mathrm{O}\right)_{0.45}$ (3): calcd. C 31.29, $\mathrm{H}$ 2.20, N 3.58; found: C 30.71, H 2.80, N 3.59. IR spectrum $\left(\mathrm{cm}^{-1}\right)$ : 3063 (w), 1623 (m), 1562 (w), 1363 (s), 1209 (m), 1103 (w), $941(\mathrm{w}), 822(\mathrm{w}), 740(\mathrm{~m}), 711(\mathrm{~s}), 564(\mathrm{w}), 439(\mathrm{w})$.

$\mathrm{Er}(\mathrm{btc})(\mathrm{DABCO})_{0.15}\left(\mathrm{H}_{2} \mathrm{O}\right)_{0.85}(4)$ was prepared using similar procedures to those described above for the preparation of 2 , except that ED was replaced with DABCO and the amine was heated at $40{ }^{\circ} \mathrm{C}$ to allow for its dissolution. Er(btc)(DABCO) ${ }_{0.15}\left(\mathrm{H}_{2} \mathrm{O}\right)_{0.85}$ (4): calcd. C 29.25, H 1.61, N 1.03; found: C 28.58, H 1.86, N 0.95. IR spectrum ( $\left.\mathrm{cm}^{-1}\right): 3060(\mathrm{w})$, 1618 (m), 1561 (w), 1448 (m), 1363 (s), 1208 (m), 1102 (w), $940(\mathrm{w}), 824(\mathrm{w}), 752(\mathrm{~m}), 710(\mathrm{~s}), 564(\mathrm{w}), 534(\mathrm{w}), 442(\mathrm{w})$.

\subsection{General procedure for Knoevenagel condensation reaction}

The amine-grafted MOF-catalyzed Knoevenagel condensation reactions of aldehydes and active methylene compounds were conducted in magnetically stirred round bottom flasks 
fitted with a reflux condenser. In a typical reaction, a mixture of cyclohexane $(10 \mathrm{~mL})$, benzaldehyde $(1 \mathrm{mmol})$, and malononitrile $(1.1 \mathrm{mmol})$ was added to a $50 \mathrm{~mL}$ flask containing catalyst 2 ( $6 \mathrm{mg}, 1 \mathrm{~mol} \%$ ). The concentration of the catalyst was calculated with respect to the molar ratio of the terminal amino group to the aldehyde. For comparison, the amounts of the other catalysts were also calculated based on the molar amounts of the amino groups available for the reaction (8 and $27 \mathrm{mg}$ for $\mathbf{3}$ and $\mathbf{4}$, respectively). The resulting mixture was stirred at $40{ }^{\circ} \mathrm{C}$ for $2 \mathrm{~h}$. The catalyst was then separated from the reaction mixture by centrifugation, and washed with ethyl acetate $(5 \times 2 \mathrm{~mL})$ to remove any physically adsorbed reagents. The catalyst was then dried at room temperature for $6 \mathrm{~h}$ and reused in the next run. The filtrate was concentrated under reduced pressure to give the crude Knoevenagel product as a residue, which was purified by flash column chromatography over silica gel to give the pure product. The pure product was characterized by ${ }^{1} \mathrm{H}$ NMR using 1,3,5-trimethylbenzene as an internal standard.

\section{Results and discussion}

\subsection{Catalyst characterization}

The X-ray diffraction pattern, thermogravimetric analysis curve, and IR spectrum of the Ln-MOF (1) material prepared in the current study were in agreement with those reported in the literature [31], except for the number of DMF molecules in the channels. In 1, the Er(III) ion was coordinated to seven oxygen atoms, with six oxygen atoms from the six carboxylate groups of the six btc ligands and one oxygen atom from the terminal water molecule in a distorted pentagonal-bipyramidal coordination sphere. Each btc ligand was bound to six different $\operatorname{Er}($ III) ions with each carboxylate oxygen connected to one $\operatorname{Er}($ III) ion, leading to the formation of a $1 \mathrm{D}$ channel $(0.7 \mathrm{~nm} \times 0.7 \mathrm{~nm})$ running along the $c$-axis. The coordinated water molecules pointing towards the channels and the guest DMF molecules in the channels could be readily removed to expose the empty coordination sites of the $\operatorname{Er}($ III) ions, which could then be subjected to further PSM processes with the diamine ligand. More importantly, this MOF material showed a very high thermal stability of more than $500^{\circ} \mathrm{C}$ (Fig. 1).

As shown in Fig. 1, the TGA curve for 2 revealed that this material underwent an $11 \%$ mass loss from 25 to $300{ }^{\circ} \mathrm{C}$, which was attributed to the loss of the coordinated ED and water molecules in the channels. In contrast, the TGA curve for $\mathbf{3}$ showed that the coordinated PP and water molecules were lost before $250^{\circ} \mathrm{C}$, whilst almost all of the coordinated DABCO and water molecules were lost from 4 before $100{ }^{\circ} \mathrm{C}$. Furthermore, the occurrence of PSM processes did not influence the stability of the structural framework of 1 , and catalysts 2,3 , and 4 were found to be stable up to $500{ }^{\circ} \mathrm{C}$. The PXRD patterns of 2,3 , and 4 were similar to that of the pristine sample of $\mathbf{1}$ (Fig. 2), which indicated that the structural framework of the pre-functionalized MOF had not changed significantly following the PSM process. Indeed, all three catalysts were found to be stable in the solid state under ambient conditions for $30 \mathrm{~d}$.

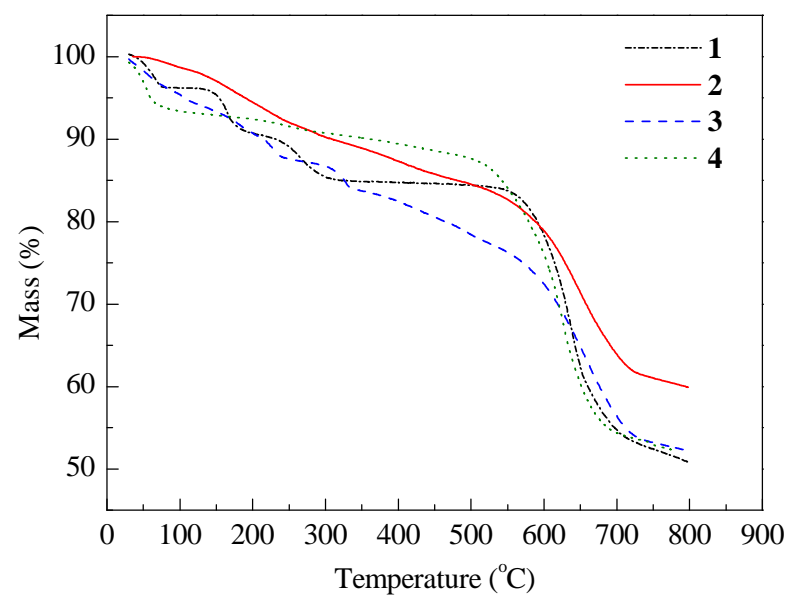

Fig. 1. TGA curves for Ln-MOF (1) and catalysts 2, 3, and 4.

Although all of the coordinated water and DMF molecules in 1 could be removed under vacuum following at $180{ }^{\circ} \mathrm{C}$ for $8 \mathrm{~h}$, the coordinatively unsaturated $\operatorname{Er}($ III) ions in the channels of catalysts $\mathbf{2}, \mathbf{3}$, and $\mathbf{4}$ could not all be coordinated by the nitrogen atoms of their respective diamines, because the simultaneous grafting of the amines would be restricted in the limited channels of $\mathbf{1}$. This process would therefore result in the partial coordination of water molecules to the non-grafted Er(III) ions if the material was exposed to air. The volumes of the three different diamines increased depending of the number of $-\mathrm{CH}_{2} \mathrm{CH}_{2}$ - groups between their two $\mathrm{N}$ atoms. The primary amine ED had the smallest volume of the three amines tested in the current study and could therefore move into the channels much more readily to form a strong coordinate bond to the coordinatively unsaturated $\operatorname{Er}($ III) ions. For this reason, the loading ratio of 2 reached 75\% (i.e., about 75\% of the Er(III) ions were grafted to ED, with the other $25 \%$ being coordinated with water molecules). Given that the volume of the secondary amine PP is larger than that of ED, it would be more difficult for the PP molecules to move into the channels to reach the Er(III) ions. This difference in the volumes of the ED and PP amines resulted in a lower loading ratio of about $55 \%$ for 3 . Furthermore, the volume of the tertiary amine DABCO is larger than

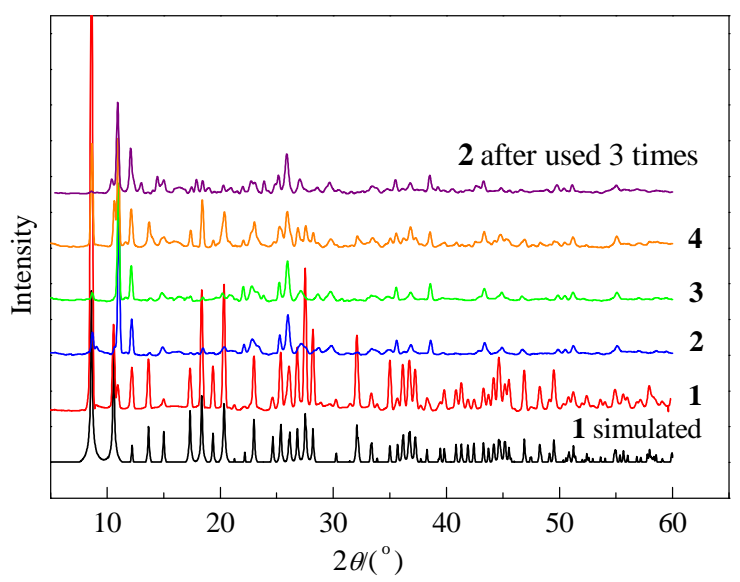

Fig. 2. PXRD patterns of $1,2,3$, and 4 . 
those of PP and ED, which resulted in $\mathbf{4}$ having the lowest loading ratio among the three catalysts, with only $15 \%$ of the Er(III) ions being grafted onto DABCO.

The surface area and pore volume of $\mathbf{1}$ were determined to be $2000 \mathrm{~m}^{2} / \mathrm{g}$ and $0.75 \mathrm{~cm}^{3} / \mathrm{g}$, respectively, based on its $\mathrm{N}_{2}$ adsorption isotherm at $-196^{\circ} \mathrm{C}$ (Fig. 3). The mean pore size of 1 was determined to be $0.65 \mathrm{~nm}$ using the Horvath-Kawazoe model. This value was consistent with the results of the single crystal structure analysis. Compared with $\mathbf{1}$, catalyst $\mathbf{2}$ exhibited a significant decrease in the amount of $\mathrm{N}_{2}$ adsorbed at $p / p_{0}>$ 0.01 , as well as a decrease in its surface area from 2000 to 650 $\mathrm{m}^{2} / \mathrm{g}$ after the grafting process. The pore size distribution curves of the different catalysts revealed that the amine grafting process led to a significant decrease in their pore sizes. Furthermore, catalysts $\mathbf{3}$ and $\mathbf{4}$ exhibited negligible $\mathrm{N}_{2}$ adsorption capacities, most likely because the channels in the structural frameworks of these catalysts were occupied by the larger PP and DABCO bases.

\subsection{Catalytic properties}

The Knoevenagel condensation reaction was selected as a suitable reaction to evaluate the heterogeneous catalytic behavior for the three solid base catalysts 2, 3, and 4. The Knoevenagel condensation reaction is not only well known as a good model for weak base-catalyzed reactions, but is also well known in terms of its application for the synthesis of $\alpha, \beta$-unsaturated carbonyl compounds from aldehydes/ketones and active methylene compounds [32-34]. In this study, we used a 1:1.1 molar ratio of benzaldehyde to malononitrile in cyclohexane with a catalyst loading of $1 \mathrm{~mol} \%$ without any prior treatment. As a control experiment, all the free amines (i.e., ED, PP, and DABCO) were evaluated in terms of their catalytic performance in the Knoevenagel reaction, and the results revealed that they performed effectively. As shown in Table 1, the Knoevenagel condensation of benzaldehyde and malononitrile in the presence of catalyst $\mathbf{2}$ gave an NMR conversion of $>$ 99\%, while catalysts $\mathbf{3}$ and $\mathbf{4}$ exhibited lower catalytic activity (93 and 63\%, respectively). These results showed that the three amine-grafted catalysts exhibited efficient catalytic activity for the Knoevenagel reaction of benzaldehyde and active malononitrile. Notably, the Knoevenagel reaction of these two

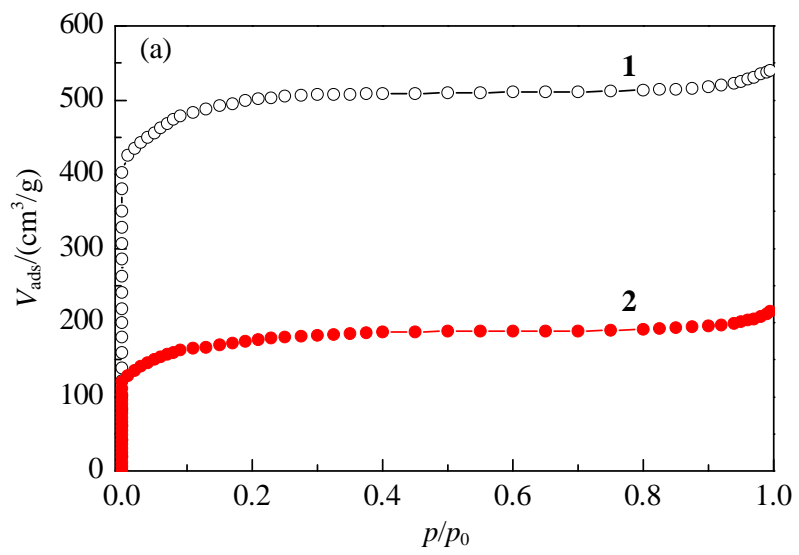

Table 1

Catalytic performance of the different catalysts ${ }^{\mathrm{a}}$

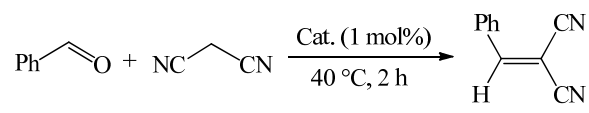

\begin{tabular}{lccc}
\hline \multirow{2}{*}{ Catalyst } & \multicolumn{3}{c}{ Conversion $^{\mathrm{b}}(\%)\left(\mathrm{TOF}^{\mathrm{c}}\left(\mathrm{min}^{-1}\right)\right)$} \\
\cline { 2 - 4 } & 1st run & 2nd run & 3rd run \\
\hline ED & $>99$ & - & - \\
PP & $>99$ & - & - \\
DABC0 & $>99$ & - & - \\
$\mathbf{1}$ & $<3$ & $98(1.26)$ & - \\
$\mathbf{2}$ & $>99(1.33)$ & $74(0.99)$ & $55(1.24)$ \\
$\mathbf{3}$ & $93(1.30)$ & $22(0.28)$ & - \\
$\mathbf{4}$ & $63(0.88)$ & - & - \\
\hline
\end{tabular}

a All of reactions were performed with benzaldehyde (1 $\mathrm{mmol})$ and malononitrile $(1.1 \mathrm{mmol})$ in $2 \mathrm{~mL}$ of cyclohexane using catalyst (1 $\operatorname{mol} \%$ ) at $40{ }^{\circ} \mathrm{C}$ for $2 \mathrm{~h}$.

b Determined by ${ }^{1} \mathrm{H}$ NMR using 1,3,5-trimethylbenzene as an internal standard.

cTurnover frequency calculated as moles of product formed per mole of free $\mathrm{N}$ atoms in the grafted MOF per minute during the first hour of the reaction.

substrates gave an NMR conversion of $<3 \%$ in the presence of the non-grafted-amine MOF 1 , which suggested that the presence of a basic catalytic site was essential to the activity of these catalysts. GC-MS analysis of the filtrate following the filtration of catalyst $\mathbf{2}$ from the reaction mixture showed that it did not contain any free ED. However, free PP and free DABCO were detected in the filtrates of the reactions catalyzed by 3 and 4 , respectively, which indicated that some of the amine molecules grafted to catalysts $\mathbf{3}$ and $\mathbf{4}$ had leached from the framework into the liquors. These results therefore suggested that the poorer catalytic performance of $\mathbf{3}$ and $\mathbf{4}$ compared with 2 could be attributed to the leaching of the amines from the frameworks of these catalysts. The use of ketones in the Knoevenagel condensation reaction instead of benzaldehydes was also investigated using similar experimental conditions. Unfortunately, however, ketones exhibited much weaker reactivity towards malononitrile, most likely because of the lower reactivity of ketones.

The reusability of the three amine-grafted catalysts was also examined. Catalyst $\mathbf{2}$ was readily separated from the reaction mixture by centrifugation following the first run. The catalyst

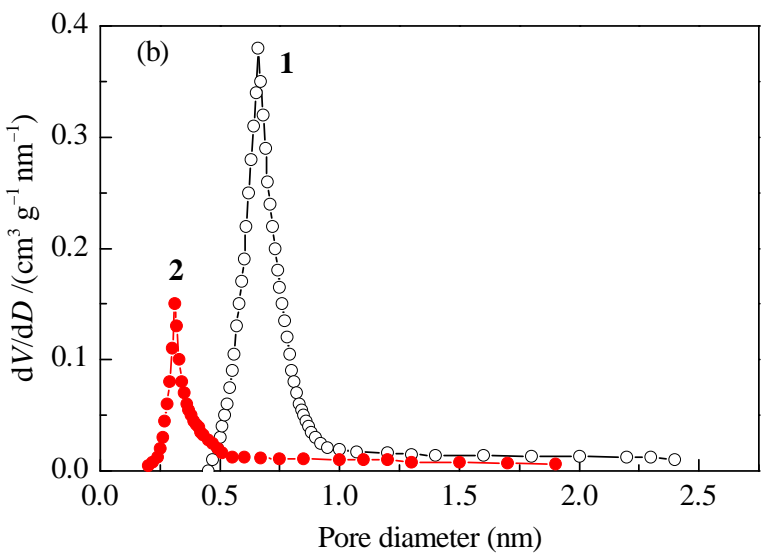

Fig. 3. Nitrogen adsorption isotherms (a) and micropore size distributions (b) of $\mathbf{1}$ and $\mathbf{2}$. 
was then washed with ethyl acetate $(5 \times 2 \mathrm{~mL})$ to remove any physically adsorbed reagents and dried at room temperature for $6 \mathrm{~h}$ before being used again in a subsequent run. Pleasingly, recycled catalyst 2 could be reused up to two times without any discernible reduction in its catalytic efficiency. For example, recycled catalyst 2 gave conversions of 98 and $96 \%$ for its second and third runs, respectively (Table 1). The PXRD pattern of recovered catalyst $\mathbf{2}$ showed that the structural integrity of the MOF remained almost unchanged after the catalytic reaction (Fig. 2). Recycling studies on catalysts $\mathbf{3}$ and $\mathbf{4}$ were also performed. However, recycled catalyst $\mathbf{3}$ gave a low conversion of only $55 \%$ after its third reaction. Furthermore, recycled catalyst 4 gave a much lower conversion of $22 \%$ for its second run. These results therefore revealed that catalysts $\mathbf{3}$ and $\mathbf{4}$ were unstable and that their grafted-amines were rapidly leaching from the channels of their MOFs to the liquor phase during the reaction, leading to a significant reduction in their amineloading and catalytic efficiency.

A major problem for solid catalysts is the possibility that some of their active sites can migrate from the solid support to the liquid phase during the reactions and that these leached species are actually responsible for a significant part of the observed catalytic activity. With this in mind, we conducted leaching tests to determine whether the grafted-amino groups in catalysts $\mathbf{2}, \mathbf{3}$, and $\mathbf{4}$ could leach from their MOF to the liquid phase during the course of the reaction. Briefly, the liquid phase of the reaction mixture was collected by centrifugation when the reaction reached $65 \%$ conversion with respect to the benzaldehyde (after 0.5 h, Fig. 4). The reaction solution was then transferred to a new reactor vessel and stirred for an additional $1.5 \mathrm{~h}$, with small samples being taken for analysis at different time intervals. The results of this experiment showed that the reaction over catalyst $\mathbf{2}$ did not proceed any further in the absence of the catalyst, which excluded the presence of an active catalytic species in the solution. In contrast, the results of leaching experiments with catalysts 3 and $\mathbf{4}$ revealed that the filtrates from these reactions continued to react in the absence of the solid catalysts under similar reaction conditions. These results were therefore in accordance with those of the reusability tests with catalysts $\mathbf{3}$ and $\mathbf{4}$. Taken together with the re-

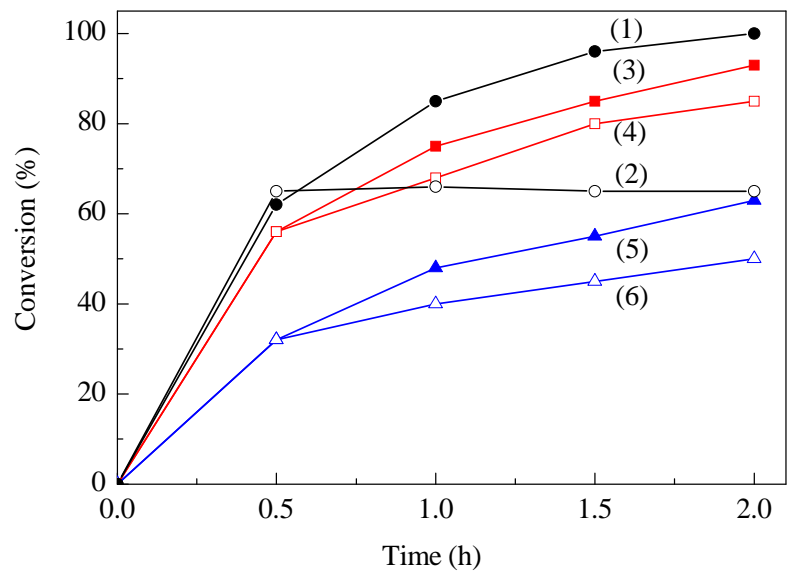

Fig. 4. Leaching tests for catalysts 2,3 , and 4 . Standard reactions with 2 (1), 3 (3), and 4 (5); Leaching tests with 2 (2), 3 (4), and 4 (6). sults for the PXRD patterns of these catalysts, we can conclude that the ED-grafted catalyst $\mathbf{2}$ was the only one of the three catalysts to exhibited genuine heterogeneous behavior as a catalyst towards the Knoevenagel condensation reaction.

To determine whether the catalytic reaction occurred inside the pores of catalyst $\mathbf{2}$ or on its surface, we investigated the Knoevenagel condensation reactions of a variety of different aldehydes with different size and shape. The reactions of benzaldehyde and para-substituted benzaldehydes proceeded smoothly to give the desired products with very high yields (Table 2, entries 1-3). However, the use of 9-anthraldehyde as a substrate led to a much lower conversion of only 59\% (Table 2 , entry 4). This reduction in the conversion was attributed to the steric hindrance of the anthracene group, which would have made it difficult for the carbanion intermediate to attack the carbonyl group of the aldehyde. When larger nitrile compounds containing active methylene groups were used as substrates in the Knoevenagel reaction with benzaldehyde (Table 2 , entries 5-7), there was a significant decrease in the conversions as the size of nitrile increased. For example, the use of tert-butyl cyanoacetate as a substrate failed to provide any of the desired condensation product, presumably because of its larger molecular volume. For comparison, we also conducted the same reaction in the presence of the homogeneous organic catalyst, ED (the molar amount of amine group was the same as

Table 2

Size-selective catalytic performances of $\mathbf{2}$ a.

(10)

${ }^{a}$ All of these reactions were performed with aldehyde $(1 \mathrm{mmol})$ and nitrile $(1.2 \mathrm{mmol})$ in $2 \mathrm{~mL}$ of cyclohexane using catalyst $(1 \mathrm{~mol} \%)$ at $40^{\circ} \mathrm{C}$ for $2 \mathrm{~h}$.

${ }^{\mathrm{b}}$ Determined by ${ }^{1} \mathrm{H}$ NMR using 1,3,5-trimethylbenzene as an internal standard.

cTurnover frequency calculated as moles of product formed per mole of free $\mathrm{N}$ atoms in the grafted MOF per minute during the first hour of the reaction.

dUsing ED (1 mol\%) as catalyst. 


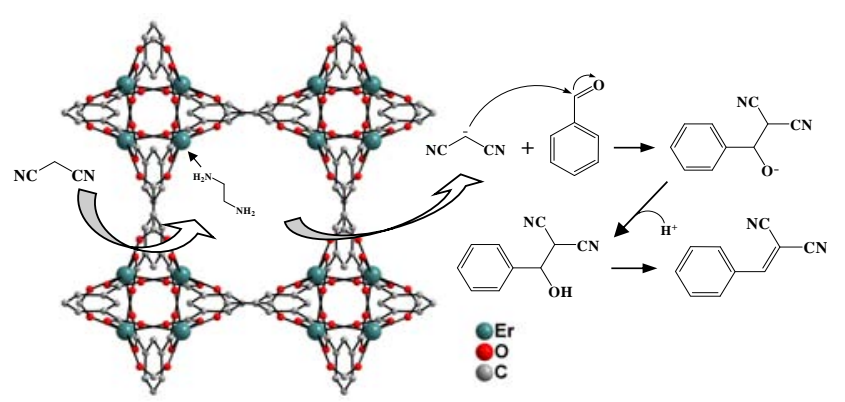

Scheme 2. Catalytic mechanism of the Knoevenagel condensation reaction catalyzed by 2 .

in 2). In this particular case, the conversion was $78 \%$ (Table 2, entry 8). These results therefore suggest that the success of the Knoevenagel condensation reactions catalyzed by $\mathbf{2}$ is highly dependent on the pore size of the MOF, with large substrates being excluded from the catalytic process because they cannot diffuse into the channels of the MOF. These results indicate that it is necessary for the nitrile substrate, but not the aldehyde, to enter the channels of the MOF and trigger the catalytic reaction. Based on these results, we have proposed a plausible catalytic mechanism for the Knoevenagel condensation reaction catalyzed by $\mathbf{2}$, which is shown in Scheme 2. According to this mechanism, the active methylene compound would initially enter the channels of the MOF and interact with the grafted ED to generate a carbanion intermediate. This carbanion intermediate would then react with the carbonyl carbon atom of the benzaldehyde substrate to produce the product. The success of this reaction process is dependent on the active methylene compound being able to access the channels of the MOF. The volume of the active methylene compound must therefore be small enough to access the channels of the MOF to allow the reaction to proceed.

Table 3 shows a comparison of the work in this study with the results in several different studies for the Knoevenagel condensation reaction between benzaldehyde and ethyl cyanoacetate in the presence of a MOF-based solid catalyst. The results of this comparison clearly show that catalyst $\mathbf{2}$ provided the best performance of all of the MOF-based catalysts tested in terms of its high TOF value.

\section{Conclusions}

We have investigated the post-synthetic modification of a robust lanthanide-based MOF, which led to the production of a series of solid base catalysts, whilst preserving the structural integrity of the MOF. The ED-grafted catalyst 2 had a high loading of diamine and exhibited high thermal stability and permanent porosity, making it an effective heterogeneous catalyst in the Knoevenagel condensation reaction. This catalyst could also be readily recovered and recycled in subsequent runs without any discernible decrease in its activity. In contrast, catalysts $\mathbf{3}$ and $\mathbf{4}$, which were based on PP and DABCO, respectively, were found to be unstable, with the grafted-amines readily leaching from the channels of the MOFs into the liquor phase during the catalytic reaction, making them behave as homogeneous catalysts.

\section{References}

[1] O'Keeffe M, Yaghi O M. Chem Rev, 2012, 112: 675

[2] Li J R, Sculley J, Zhou H C. Chem Rev, 2012, 112: 869

[3] Ma L Q, Abney C, Lin W B. Chem Soc Rev, 2009, 38: 1248

[4] Cook T R, Zheng Y R, Stang P J. Chem Rev, 2013, 113: 734

[5] Cui Y J, Yue Y F, Qian G D, Chen B L. Chem Rev, 2012, 112: 1126

[6] Shi D B, Ren Y W, Jiang H F, Cai B W, Lu J X. Inorg Chem, 2012, 51: 6498

[7] Liu J W, Chen L F, Cui H, Zhang J Y, Zhang L, Su C Y. Chem Soc Rev, 2014, 43: 6011

[8] Sharma M K, Singh P P, Bharadwaj P K. J Mol Catal A, 2011, 342-343: 6

[9] Ren Y W, Liang J X, Lu J X, Cai B W, Shi D B, Qi C R, Jiang H F, Chen J, Zheng D. Eur J Inorg Chem, 2011: 4369

[10] Cai B W, Ren Y W, Jiang H F, Zheng D, Shi D B, Qian Y Y, Hu H X. Inorg Chem Commun, 2012, 15: 159

[11] Cai B W, Ren Y W, Jiang H F, Zheng D, Shi D B, Qian Y Y, Chen J. CrystEngComm, 2012, 14: 5285

[12] Shi D B, Ren Y W, Jiang H F, Cai B W, Lu J X. Inorg Chem Commun, 2012, 24: 114

[13] Gustafsson M, Bartoszewicz A, Martín-Matute B, Sun J L, Grins J, Zhao T, Li Z Y, Zhu G S, Zou X D. Chem Mater, 2010, 22: 3316

[14] Zhang J, Huang J, Yang J, Chen H J. Inorg Chem Commun, 2012, 17: 163

[15] Lin Z J, Yang Z, Liu T F, Huang Y B, Cao R. Inorg Chem, 2012, 51:

Table 3

Comparison of the Knoevenagel condensation reaction of benzaldehyde and ethyl cyanoacetate in the presence of different MOF-based catalysts.

\begin{tabular}{|c|c|c|c|c|c|c|}
\hline Catalyst & Catalyst loading a (\%) & Temperature $\left({ }^{\circ} \mathrm{C}\right)$ & Time (h) & Conversion (\%) & TOF b $\left(\mathrm{min}^{-1}\right)$ & Ref. \\
\hline $\operatorname{Er}($ btc $)(E D)_{0.75}\left(\mathrm{H}_{2} \mathrm{O}\right)_{0.25}$ & 1.1 & 40 & 2 & 98 & 1.30 & this work \\
\hline ED grafted MIL-101 & 2.1 & 80 & 19 & 98 & 0.041 & [24] \\
\hline IRMOF-3 & 2.6 & 40 & 1 & 99 & 0.635 & [35] \\
\hline $\mathrm{Zn}_{2}(\mathrm{tpt})_{2}(2-\mathrm{atp}) \mathrm{I}_{2} \mathrm{c}$ & 0.5 & 60 & 2 & 37 & 0.617 & {$[36]$} \\
\hline ZIF-9d & 5 & 25 & 4 & 100 & 0.083 & [37] \\
\hline Fe-MIL-101- $\mathrm{NH}_{2} \mathrm{e}$ & 15.1 & 80 & 24 & 98 & 0.0103 & [38] \\
\hline
\end{tabular}

a The catalyst loading was calculated as the molar ratio of catalytically active groups to substrates.

b Turnover frequency calculated as moles of product formed per mole of catalytically active group per minute.

${ }^{c}$ tpt $=$ tris(4-pyridyl)triazine; 2 -atp $=2$-aminoterephthalate.

d Benzaldehyde and malononitrile were used as the substrates.

e The composition of this MOF was $\mathrm{Fe}_{3} \mathrm{OCl}\left(\mathrm{H}_{2} \mathrm{O}\right)_{2}\left(\text { bdc }-\mathrm{NH}_{2}\right)_{3} ; \mathrm{H}_{2}$ bdc- $\mathrm{NH}_{2}=2$-aminoterephthalic acid. 


\title{
Graphical Abstract
}

Chin. J. Catal., 2015, 36: 1949-1956 doi: 10.1016/S1872-2067(15)60945-7

\section{Amine-grafted on lanthanide metal-organic frameworks: Three solid base catalysts for Knoevenagel condensation reaction}

Yanwei Ren*, Jiaxian Lu, Ou Jiang, Xiaofei Cheng, Jun Chen

South China University of Technology; Guangdong Winner Functional Materials Co., Ltd

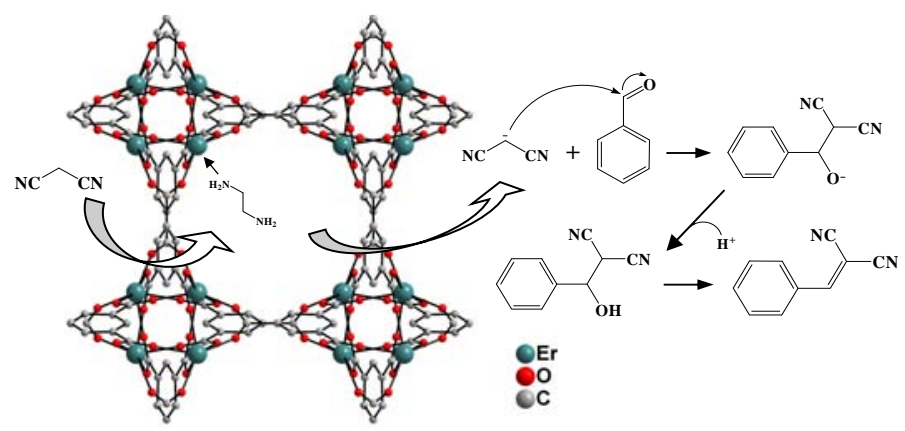

1,2-Ethanediamine was grafted into the channels of a lanthanide metal-organic framework (MOF) using a post-synthetic modification strategy, and the resulting material performed as a highly effective and recyclable heterogeneous catalyst in the Knoevenagel condensation reaction.

1813

[16] Li Y X, Xue M, Guo L J, Huang L, Chen S R, Qiu S L. Inorg Chem Commun, 2013, 28: 25

[17] Wang Z Q, Cohen S M. Chem Soc Rev, 2009, 38: 1315

[18] Cohen S M. Chem Rev, 2012, 112: 970

[19] Corma A, García H, Llabrés i Xamena F X. Chem Rev, 2010, 110: 4606

[20] Wang Z Q, Cohen S M. J Am Chem Soc, 2007, 129: 12368

[21] Costa J S, Gamez P, Black C A, Roubeau O, Teat S J, Reedijk J. Eur J Inorg Chem, 2008: 1551

[22] Ahnfeldt T, Gunzelmann D, Loiseau T, Hirsemann D, Senker J, Férey G, Stock N. Inorg Chem, 2009, 48: 3057

[23] Garibay S J, Wang Z Q, Cohen S M. Inorg Chem, 2010, 49: 8086

[24] Hwang Y K, Hong D Y, Chang J S, Jhung S H, Seo Y K, Kim J, Vimont A, Daturi M, Serre C, Férey G. Angew Chem Int Ed, 2008, 47: 4144

[25] Huang Y B, Zheng Z L, Liu T F, Lü J, Lin Z J, Li H F, Cao R. Catal Commun, 2011, 14: 27

[26] Tanabe K K, Wang Z Q Cohen S M. J Am Chem Soc, 2008, 130: 8508

[27] Demessence A, D’Alessandro D M, Foo M L, Long J R. J Am Chem
Soc, 2009, 131: 8784

[28] Canivet J, Aguado S, Daniel C, Farrusseng D. ChemCatChem, 2011, 3: 675

[29] Vermoortele F, Ameloot R, Vimont A, Serre C, De Vos D. Chem Commun, 2011, 47: 1521

[30] Banerjee M, Das S, Yoon M, Choi H J, Hyun M H, Park S M, Seo G, Kim K. J Am Chem Soc, 2009, 131: 7524

[31] Jiang H L, Tsumori N, Xu Q. Inorg Chem, 2010, 49: 10001

[32] Angeletti E, Canepa C, Martinetti G, Venturello P. Tetrahedron Lett, 1988, 29: 2261

[33] Parida K M, Rath D. J Mol Catal A, 2009, 310: 93

[34] Tran U P N, Le K K A, Phan N T S. ACS Catal, 2011, 1: 120

[35] Gascon J, Aktay U, Hernandez-Alonso M D, Van Klink G P M, Kapteijn F. J Catal, 2009, 261: 75

[36] Tan Y, Fu Z Y, Zhang J. Inorg Chem Commun, 2011, 14: 1966

[37] Nguyen L T L, Le K K A, Truong H X, Phan N T S. Catal Sci Technol, 2012, 2: 521

[38] Hartmann M, Fischer M. Microporous Mesoporous Mater, 2012, 164: 38

\section{有机胺修饰稀土金属有机骨架: 用于Knoevenagel缩合反应的三种固体碱催化剂}

\author{
任颜卫 ${ }^{\mathrm{a},}{ }^{*}$, 陆家贤 ${ }^{\mathrm{a}}$, 江 鸥 ${ }^{\mathrm{b}}$, 程晓飞 ${ }^{\mathrm{a}}$, 陈 俊 ${ }^{\mathrm{b}}$ \\ a 华南理工大学化学与化工学院, 广东广州510641 \\ $\mathrm{b}$ 广东炜林纳新材料科技股份有限公司, 广东佛山528521
}

摘要: 稀土金属有机骨架(Ln-MOFs) 是利用有机配体和稀土离子之间配位自组装形成的具有超分子多孔网络结构的类沸石材料, 其优点是稳定性好, 一般不溶于常规的有机和无机溶剂, 并且孔径、孔形及孔表面性质可通过其构建分子的选择或修饰进行灵活 设计和制备. 稀土离子性能独特, 有机配体种类繁多, 将稀土离子与有机配体可控组装可获得许多结构多样、性能优异的Ln-MOFs 材料. 这些功能材料已在气体吸附与分离、发光器件、化学传感以及磁性材料等多方面显示出潜在应用价值. 特别是Ln-MOFs材 料作为非均相催化剂具有热稳定性高、比表面积大以及稀土离子配位环境多样等优点,近年来受到国内外研究者关注和重视. 后 合成修饰法(PSM)是利用MOFs骨架中不饱和配位的金属离子或潜在的有机反应基团,通过配位键或共价键方式引入有机或无机 分子,制备具有新功能的骨架材料.

本文采用PSM策略,将三种不同的有机二胺后合成修饰到具有配位不饱和位点的稀土金属有机骨架[Er(btc)]的孔道中, 得到 三种固体碱催化剂: $\operatorname{Er}(\mathrm{btc})(\mathrm{ED})_{0.75}\left(\mathrm{H}_{2} \mathrm{O}\right)_{0.25}(2), \operatorname{Er}(\mathrm{btc})(\mathrm{PP})_{0.55}\left(\mathrm{H}_{2} \mathrm{O}\right)_{0.45}(3)$ 和 $\mathrm{Er}(\mathrm{btc})(\mathrm{DABCO})_{0.15}\left(\mathrm{H}_{2} \mathrm{O}\right)_{0.85}(4)$. 其中, btc 为1,3,5-均苯三 
甲酸, $\mathrm{ED}$ 为乙二胺, $\mathrm{PP}$ 为哌嗪, $\mathrm{DABCO}$ 位为三乙烯二胺. 单晶结构分析表明, 在 $\left[\operatorname{Er}(\mathrm{btc})\left(\mathrm{H}_{2} \mathrm{O}\right)\right] \cdot \mathrm{DMF}_{0.7}(\mathbf{1})$ 中, 铒离子与六个btc配体的 六个羧酸氧原子和一个水分子配位,形成变形的五角双雉几何构型. 每个btc配体连接六个铒离子构成具有一维开放孔道 $(0.7 \mathrm{~nm} \times$ $0.7 \mathrm{~nm}$ )的三维立体结构. 重要的是, 孔道中的配位水分子和游离DMF分子可通过真空加热除去而不影响其骨架结构(热稳定性达 $500^{\circ} \mathrm{C}$ ), 这将有利于对其进行后合成修饰. 热重分析(TGA)表明, 催化剂 2 在 $25-300^{\circ} \mathrm{C}$ 失去孔道中配位的乙二胺和水分子; 催化剂3 在 $250{ }^{\circ} \mathrm{C}$ 前失去孔道中的哌嗪和水分子; 催化剂 4 则在 $100{ }^{\circ} \mathrm{C}$ 前失去孔道中配位的三乙烯二胺和水分子. 粉末 $\mathrm{X}$ 射线衍射 (PXRD)结果显示, 后合成修饰过程并没有改变催化剂骨架的稳定性, 其稳定性在空气中超过 30 d. 氮气吸附实验表明, Ln-MOF 1 的 比表面积和孔体积分别为 $2000 \mathrm{~m}^{2} / \mathrm{g}$ 和 $0.75 \mathrm{~cm}^{3} / \mathrm{g}$, 平均孔尺寸为 $0.65 \mathrm{~nm}$, 与晶体结构分析结果基本一致. 相比之下, 后合成修饰的催 化剂 2 的比表面积明显降低, 为 $650 \mathrm{~m}^{2} / \mathrm{g}$, 而催化剂 3 和 4 由于后修饰较大体积的二胺分子(哌嗪和三乙烯二胺), 表现出可忽略的氮气 吸附能力. 上述结果表明,催化剂2具有较高的有机胺负载量、较高的热稳定性和多孔性.

采用苯甲醛和丙二腈的Knoevenagel缩合反应研究了三种固体碱的非均相催化能力. 结果表明,在相同反应条件下,催化剂 2 具 有很好的首次催化能力(99\%), 优于催化剂3(93\%)和4(63\%). 并且,催化剂2循环使用三次后, 催化能力几乎没有改变, 而催化剂3和 $\mathbf{4}$ 的催化能力则逐渐降低, 催化剂 $\mathbf{4}$ 在第三次使用时已无催化能力. 滤出实验显示, 催化剂 $\mathbf{2}$ 在反应过程中无活性物种离去进入液相 体系中, 即无乙二胺分子从催化剂骨架孔道中离去, 证明其为非均相催化本质. 而催化剂 $\mathbf{3}$ 和 4 则在反应过程中有二胺分子离去, 进 入反应液相中, 从而导致其循环使用催化能力降低. 催化剂 $\mathbf{2}$ 的底物择形催化反应结果显示, 先是丙二腈分子进入催化剂孔道中, 形 成碳负离子, 然后亲核进攻醅分子生成产物. 因此, 体积较大的腈衍生物因不能进入孔道而不能发生反应, 而体积较大的醛分子则 不受影响,能顺利地发生反应.

关键词: 稀土金属有机骨架; 后合成修饰; 固体碱催化剂; Knoevenagel缩合反应; 择形催化

收稿日期: 2015-05-29. 接受日期: 2015-07-03. 出版日期: 2015-11-20.

*通讯联系人. 电话: (020)87112053; 传真: (020)87113735; 电子信箱: renyw@scut.edu.cn

基金来源：国家自然科学基金(21372087).

本文的英文电子版由Elsevier出版社在ScienceDirect上出版(http://www.sciencedirect.com/science/journal/18722067). 